\title{
The effect of different reinforcements on the fracture toughness of materials for interim restorations
}

Greta A.V.M. Geerts, BChD, PDD, MChD, ${ }^{\mathrm{a}}$ Jan-Hendrik Overturf, BChD, MChD, ${ }^{\mathrm{b}}$ and Theuns G. Oberholzer, BChD, MSc, $\mathrm{PhD}^{\mathrm{c}}$

Statement of problem. Fracture of an interim fixed partial denture (FPD) may jeopardize the success of the interim prosthodontic treatment phase and cause patient discomfort.

Purpose. The purpose of this study was to compare the fracture toughness of a polymethyl methacrylate (PMMA) resin and a bis-acryl composite (BAC) resin reinforced with stainless steel wire, glass, and polyethylene fiber.

Material and methods. Four groups $(n=13)$ of each of the 2 materials were prepared for the single-edge 3-point-bending test. Three groups had the different reinforcements, and the group without reinforcement served as control. Using a universal testing machine, peak load to fracture was recorded and fracture toughness $\left(\mathrm{K}_{\mathrm{IC}}\right)$ was calculated in $\mathrm{MNm}^{-1.5}$. Median $\mathrm{K}_{\mathrm{IC}}$ values were compared by means of nonparametric ANOVA (Kruskal-Wallis test, $\alpha=.05$ ).

Results. For the controls, the fracture toughness for PMMA resin $\left(\mathrm{K}_{\mathrm{IC}}=27.9\right)$ was significantly lower $(P<.01)$ than for BAC resin $\left(K_{\mathrm{IC}}=31.2\right)$. Glass fibers and stainless steel wire reinforcements produced significantly higher fracture toughness for both PMMA ( $\mathrm{K}_{\mathrm{IC}}=34.4, P<.01$, and $\mathrm{K}_{\mathrm{IC}}=39.0, P<.001$, respectively) and $\mathrm{BAC}$ resin $\left(\mathrm{K}_{\mathrm{IC}}=42.3, P<.001\right.$, and $\mathrm{K}_{\mathrm{IC}}=44.0, P<.001$, respectively), but the polyethylene fibers $\operatorname{did}$ not $\left(\mathrm{K}_{\mathrm{IC}}=33.1\right.$, $P>.10$, for $\mathrm{BAC}$ resin and $\mathrm{K}_{\mathrm{IC}}=25.8, P>.10$, for PMMA resin). There was no significant difference between the fracture toughness of the wire and glass fiber reinforcements for both interim materials ( $P>.10$ in both instances).

Conclusions. Of the 3 reinforcement methods evaluated, wire and glass fiber reinforced the PMMA and BAC resin materials best.

\section{Clinical implications}

When esthetics and space are of concern, glass fiber seems to be the most appropriate method for reinforcing interim FPDs made from PMMA and BAC resins. Wire provides the clinician with a less expensive option in areas of the mouth where esthetics is not crucial and adequate space is available. All 3 reinforcements prevent catastrophic failure.

Polymethyl methacrylate (PMMA), polyethyl methacrylate, bis-acryl composite (BAC), and epimine resin are materials commonly used to fabricate interim fixed partial dentures (FPDs). ${ }^{1}$ These materials must be strong enough to withstand masticatory forces, particularly for long-span FPDs, for long-term use, or for patients with 
parafunctional habits. ${ }^{2,3}$ Different methods of enhancing the physical properties of interim FPDs have been developed.4 Positive results have been achieved with the use of metal and fiber reinforcements..$^{-12}$ These studies demonstrate that metal wires incorporated into polymers produce higher transverse strength, but fibers have been demonstrated to be more effective in improving strength. ${ }^{12}$ Various types of fibers have been investigated, including glass, carbon, aramid, and polyethylene fibers. The eventual strength of the reinforced resin is influenced by the quantity and orientation of the fibers, position, fiber impregnation, and adhesion of the fibers to the polymer matrix. ${ }^{13-17}$ The degree of adhesion between fiber and polymer affects the degree of reinforcement. The better the bond, the better the transfer of stress from the weak polymer matrix to the fibers with a higher tensile strength. ${ }^{18,19}$ Unidirectional fibers enhance strength and stiffness in 1 direction, while randomly oriented fibers enhance mechanical properties in all directions. ${ }^{15}$ Interim FPDs reinforced with impregnated fibers demonstrate higher fracture resistance than those reinforced with nonimpregnated fibers. ${ }^{20}$ Silanized glass fibers bond readily to polymers. ${ }^{21}$ Compared to other types of fibers, adhesion of polyethylene fibers to polymers is less effective. ${ }^{22}$

The fracture mechanism approach is considered a reliable indicator of the performance of brittle materials. ${ }^{23} \mathrm{~A}$ fracture toughness test measures the resistance of a material to crack extension. ${ }^{24}$ Different tests have been used to quantify the fracture toughness of dental materials. One such test is the single-edge notch 3-point bending test. This test determines critical values of stress intensity $\left(\mathrm{K}_{\mathrm{IC}}\right)$ when standardized precracked specimens are loaded until fracture. These loads are used to calculate toughness. ${ }^{25}$ Numerous fracture resistance tests have been performed for resins reinforced with steel wire, polyethylene, or glass fiber.5,8-15,17-21 However, none have compared the reinforcement effect of steel wire, polyethylene, and glass fiber on PMMA and BAC resin in a single study.

The purpose of this study was to compare the fracture toughness of 2 types of materials frequently used for interim FPDs, with and without reinforcement. Stainless steel wire, polyethylene fiber, and glass fiber were used as the 3 materials for reinforcement. The null hypothesis to be tested was that the 3 reinforcement materials would not significantly alter the fracture toughness of the 2 resins.

\section{Material and methods}

Four groups $(\mathrm{n}=13)$ of specimens were prepared from a BAC resin (Protemp 3 Garant; 3M ESPE, Seefeld, Germany) and a PMMA resin (Coldpac; The Motloid Co, Chicago, Ill) for a single-edge notch 3-point bending test conforming to the British Standard 5477 (1977). ${ }^{26}$ The dimensions of the specimens were $3 \mathrm{~mm} \times 6 \mathrm{~mm} \times 26 \mathrm{~mm}$. The depth of the precrack was $3 \mathrm{~mm}$, which was half the height of the specimens. Three of the 4 groups were reinforced, 1 group without reinforcement served as the control. The 
reinforcements used were: (1) 1-mm-diameter smooth stainless steel wire (KC Smith \& Co, Monmouth, UK), (2) glass fiber (everStick C\&B fiber; Stick Tech Ltd, Turku, Finland), and (3) polyethylene fiber (Construct braided polyethylene fiber; Kerr Corp, Orange, Calif).

A custom-made stainless steel mold was used to produce standardized specimens (Fig. 1). The precrack, perpendicular to the specimen length, was created by inserting a straight-edged surgical blade (No. 11; Swann-Morton Ltd, Sheffield, UK), with a blade edge radius of less than $0.3 \mu \mathrm{m}$, half the length of the mold; the slot $(\mathrm{A}=3 \mathrm{~mm})$ extended up half the height of the specimen $(\mathrm{W}=6 \mathrm{~mm})$ to give $\mathrm{A} / \mathrm{W}=0.5$ (Fig. 2). The mold used in this study could be disassembled completely so that no force was required to remove the polymerized specimens from the mold.

The control groups were fabricated as follows: the BAC resin was mixed using the automix gun system provided by the manufacturer. For the PMMA resin, $0.58 \mathrm{~g}$ of powder was weighed using a precision standard scale (Model TS400 D; Ohaus Corp, Pine Brook, NJ) and $0.25 \mathrm{ml}$ of liquid was measured using a pipette (Pipetman, L 116956; Gilson, Inc, Paris, France) and mixed. This powder-liquid ratio is lower than the recommended ratio and resulted in a softer consistency for easy flow into the mold, minimizing voids. The mold was slightly overfilled and the surface covered with a plastic matrix strip (Odus Universal Strip; Produits Dentaire SA, Vevey, Switzerland) and a thick glass plate. Hand pressure was applied for 30 seconds until contact was established with the top surface of the template, as visualized through the glass plate. The PMMA resin specimens were left to polymerize for 20 minutes (double the manufacturer's recommended time) in the mold, and an additional 10 minutes on the bench. BAC resin specimens were left to polymerize for 10 minutes (double the manufacturer's recommended time) in the mold and an additional 5 minutes for bench polymerization. After polymerization, the blade was carefully removed and the specimens were examined with a stereomicroscope (Zeiss, Oberkochen, Germany) ( $\times 10$ magnification) for the inclusion of voids or air bubbles. Specimens containing flaws were discarded and replaced. The edges of the specimens were finished with 1000-grit carbide paper (3M ESPE, St. Paul, Minn). Specimen dimensions (width, height, and length) were measured 3 times using a bench digital micrometer (Model IDC-112; Mitutoyo Co, Higashi-Hiroshima, Japan) accurate to $0.001 \mathrm{~mm} .{ }^{9}$

For the reinforced test groups, all procedures were the same as for the 2 unreinforced groups, except for the insertion of the reinforcement material parallel to the long axis of the specimens. The mold was filled to the level of the stops with 1 of the resins. The reinforcement material was placed into the unpolymerized resin and more resin was added to fill the mold, as previously described. Two lateral stops in the mold ensured that all reinforcements were inserted in the same position for all specimens. The glass 
fiber bundles with a 1.5-mm diameter were cut into 27-mm-long pieces. The fibers were light polymerized by irradiating 3 different areas of the upper surface (center, left, and right) with a halogen light unit (Megalux CS; Megadenta, Radeberg, Germany) for 40 seconds each. The tip of the light unit was held within $2 \mathrm{~mm}$ of the surface of the fiber. The unit had the following specifications: power, $82 \mathrm{~W}$; tension, 220/110 VAC; halogen lamp, $75 \mathrm{~W}$; spectrum, $400 \mathrm{~nm}-500 \mathrm{~nm}$. The polyethylene fiber braids with a width of 3 $\mathrm{mm}$ were cut into strips of $27 \mathrm{~mm}$ and impregnated with resin (according to the manufacturer's instructions). These fibers were polymerized and placed in the mold exactly as described for the glass fibers. The smooth 1-mm-diameter stainless steel wire was also cut to a length of $27 \mathrm{~mm}$ and was embedded into the resin before the mold was filled.

The specimens were stored in distilled water at $37^{\circ} \mathrm{C}$ in an oven for 24 hours before testing. The specimens were placed on the supports of the 3-point bending apparatus. The span width of the supports was $20 \mathrm{~mm}$. Mechanical loading was applied to the center of each specimen at 90 degrees to the specimen axis through a stainless steel rod attached to a universal testing machine (Model 1446; Zwick, Ulm, Germany) and 0.5-kg load cell. With a crosshead speed of $1 \mathrm{~mm} / \mathrm{s}$, the load was increased until the specimen fractured. Peak load to fracture, and specimen deflection (recorded as load/deflection curves) were recorded and fracture toughness $\left(\mathrm{K}_{\mathrm{IC}}\right.$ ), measured in $\mathrm{MNm}^{-1.5}$, was calculated using the following equation: 9

$$
\mathrm{K}_{\mathrm{IC}}=3(\mathrm{PL} / \mathrm{BW} 3 / 2) \mathrm{Y}
$$

where $\mathrm{P}$ is peak load at fracture; $\mathrm{L}$ is distance between the supports; $\mathrm{B}$ is specimen width; W is specimen height; and $\mathrm{Y}$ is $1.93(\mathrm{~A} / \mathrm{W})^{1 / 2}-3.07(\mathrm{~A} / \mathrm{W})^{3 / 2}+14.53(\mathrm{~A} / \mathrm{W})^{5 / 2}-$ $25.11(\mathrm{~A} / \mathrm{W})^{7 / 2}+25.80(\mathrm{~A} / \mathrm{W})^{9 / 2}$.

For comparative purposes, the mean and standard deviations for each test group were calculated. The medians of the values were compared (pairwise and otherwise) by means of nonparametric analysis of variance (ANOVA) (Kruskal-Wallis test) and summarized considering the Bonferroni adjustment for multiple comparisons ( $\alpha=.05$ ). The variability of the fracture toughness among the different reinforcements within the 2 groups was tested to see whether the assumptions of the Kruskal-Wallis test were violated.

\section{Results}

The descriptive statistics for the fracture toughness values for the 8 groups are summarized in Table I. All of the means were higher than the medians, indicating that there was positive skew. However, this skew was small and did not warrant data transformation. Reasons for using nonparametric ANOVA were the small specimen groups and the presence of 3 outlier values. Although the mean was higher than the median for all groups, the difference was small, except for the glass fiber reinforcement 
of PMMA. This was due to 1 high outlier value. The side-by-side box plot for PMMA demonstrates this (Fig. 3). Figure 4 presents the side-by-side box plot for the 4 BAC groups.

For the PMMA resin material, the fracture toughness of the glass fiber group displayed the largest standard deviation and interquartile range. The differences among the standard deviations of the 4 PMMA groups were not significant. The wire group exhibited the highest median and the polyethylene fiber group the lowest. This difference was significant $(P<.001)$. Compared to the control, the wire group had significantly higher fracture toughness $(P<.001)$, as did the glass fiber $(P<.01)$. The difference between glass fiber and wire reinforcement was not significant $(P>.10)$. Both the glass fiber and the wire group had significantly higher fracture toughness than the polyethylene group $(P<.001)$. Although the polyethylene fiber group demonstrated a lower fracture toughness compared to the control group, this difference was not significant.

For the BAC material, the fracture toughness of the polyethylene fiber displayed the largest standard deviation of all 4 groups. The differences among the standard deviations of the 4 groups were not significant. The control group displayed the smallest standard deviation and interquartile range. The wire group exhibited the highest median, and the glass fiber group demonstrated the highest mean. Compared to the control, the wire group had a significantly higher fracture toughness $(P<.001)$, as did the glass fiber $(P<.001)$. The fracture toughness of the wire group was significantly higher than the fracture toughness of the polyethylene fiber group $(P<.001)$, but not significantly higher than that of the glass fiber group. The fracture toughness of the glass fiber group was significantly higher than that of the polyethylene fiber $(P<.005)$. Polyethylene fibers did provide reinforcement, but the fracture toughness of the polyethylene-reinforced BAC material was not significantly higher than the unreinforced control BAC material $(P>.10)$.

Comparing the BAC and PMMA materials, the fracture toughness median for the control BAC resin was higher than for the control PMMA resin, and this was confirmed by a Kruskal-Wallis test $(P<.01)$. The 2 standard deviations were approximately equal, but the interquartile range of the BAC resin (1.91) was smaller than that of the PMMA resin (5.25). For the wire-reinforced groups, the standard deviation of the PMMA resin group was somewhat larger than the standard deviation of the BAC resin group, but the difference was not significant. For the polyethylene reinforcement, the fracture toughness median of the PMMA group was significantly lower than the median of the BAC resin group $(P<.001)$. For the glass fiber reinforcement, the standard deviation and interquartile range of the PMMA group was larger than that of the BAC resin group, but not significantly different. 
BAC resin reinforced with wire exhibited the highest median (44.02), BAC resin with glass fiber the second highest (42.31), and PMMA resin with wire (39.00) the third highest. The same 3 material combinations make up the 3 highest means, namely BAC resin with glass fiber (46.75; highest), BAC resin reinforced with wire (45.97; second highest), and PMMA resin with wire (42.74; third highest). PMMA resin reinforced with polyethylene fiber resulted in the lowest median fracture toughness (25.82) and is even weaker than the control PMMA resin (27.89; the second smallest). All reinforced groups demonstrated significantly higher fracture toughness for BAC resin than for PMMA resin (glass fiber $P<.005$; polyethylene fiber, $P<.005$; wire, $P<.005$ ).

Table I. Descriptive statistics for fracture toughness $\left(\mathrm{K}_{\mathrm{IC}}\right.$ in $\left.\mathrm{MNm}^{-1.5}\right)$ for 8 groups $(\mathrm{n}=13)$

\begin{tabular}{|c|c|c|c|c|c|c|c|c|}
\hline & \multicolumn{4}{|c|}{ PMMA Resin } & \multicolumn{4}{|c|}{ BAC Resin } \\
\hline & Control & Wire & $\mathrm{PE}$ & Glass & Control & Wire & $\mathrm{PE}$ & Glass \\
\hline Min & 25.89 & 32.47 & 24.59 & 33.27 & 30.86 & 40.93 & 22.60 & 40.43 \\
\hline Med & 27.89 & 39.00 & 25.82 & 34.44 & 31.17 & 44.02 & 33.10 & 42.31 \\
\hline $\begin{array}{l}\text { Mea } \\
\mathrm{n}\end{array}$ & 29.07 & 42.74 & 29.79 & 40.01 & $35 \cdot 32$ & $45 \cdot 97$ & $35 \cdot 77$ & 46.75 \\
\hline SD & 2.63 & 5.02 & 3.87 & 8.85 & 2.38 & 3.21 & 4.46 & 3.88 \\
\hline IQR & 5.25 & 5.85 & 2.75 & $5 \cdot 94$ & 1.91 & 3.74 & $3 \cdot 56$ & $3 \cdot 31$ \\
\hline Max & 33.79 & 50.79 & 38.22 & 62.76 & 40.72 & 53.11 & 41.41 & 52.41 \\
\hline
\end{tabular}

PMMA = polymethyl methacrylate resin, $\mathrm{BAC}=$ bis-acryl composite resin, Min = minimum, $\mathrm{Med}=$ median, $\mathrm{IQR}=$ interquartile range, $\mathrm{Max}=$ maximum, wire $=$ stainless steel wire, $\mathrm{PE}=$ polyethylene fiber, glass = glass fiber

\section{Discussion}

The null hypothesis was that the 3 reinforcements would not significantly alter the fracture toughness of the 2 resins. The data support rejection of the hypothesis for the glass fiber and the stainless steel wire, but not for the polyethylene fiber.

No interim material meets the ideal requirements for each situation. Strength is only 1 factor to consider when selecting a material for interim FPDs. Other important factors include ease of use, esthetics, marginal adaptation, shrinkage, biocompatibility, and cost. ${ }^{6}$ A strong material may lack other required characteristics, such as good color stability or ease of manipulation. A single anterior tooth restoration will have different requirements than a posterior long-span interim FPD. The clinician must choose the material and reinforcement method appropriate for each application. 
In vitro static load tests differ from the dynamic intraoral conditions. Cyclic loading can be incorporated in the testing method to simulate the clinical environment. Microcracks and defects that grow inherently during thermal and mechanical processes can significantly reduce strength measurement. ${ }^{27}$ No cyclic loading in a moist environment was performed in the present study, and this should be considered a study limitation.

BAC resins are supplied in a cartridge delivery system, presumably providing a more consistent mix than can be achieved by hand mixing the PMMA monomer and polymer. However, this could not be substantiated by Haselton et al,3 who found no lower standard deviations for the bisacrylate cartridge products compared to hand-mixed PMMA resin products. The present study confirms that the standard deviations between the BAC and the PMMA resin do not differ significantly. After filling the mold, hand pressure was applied for 30 seconds until contact was established between the glass plate and the top surface of the mold. The pressure was not standardized and this is a study limitation.

In contrast with the PMMA, BAC resins are capable of cross-linking with other monomer chains, resulting in higher strength and toughness. 3 The present study confirms the higher fracture toughness of the control BAC resin over the control PMMA resin. However, it has been found that flexural strength among different brands of the BAC resins varies greatly, with some brands having even lower values than the simpler and less expensive PMMA resin products. ${ }^{3}{ }^{6}$ Significant differences in strength were also reported among different brands of polymethyl methacrylate resin materials used for interim FPDs. 4 Therefore, comparisons of studies using different brands should be made with caution.

In the present study, the powder-liquid ratio of the PMMA resin was changed for ease of manipulation. This might have influenced the strength of the material. In practice, clinicians do not always adhere to manufacturers' recommendations and change powder-liquid ratios to modify handling properties of materials. The influence of the powder-liquid ratio on the strength of fiber-reinforced polymers is a potential topic for future research.

PMMA resin, a brittle material, has a higher compressive than tensile strength. 5 Therefore, restorations fracture on the tension side away from the occlusal load. When the tensile strength of the polymer is lower than the tensile strength of the fiber, the specimen will gain strength when the fiber is placed in the area of higher tension, away from the load. This was confirmed by Hamza et $\mathrm{al}^{2}$ in an in vitro study on the different positions of fiber in FPDs. In the present study, the fiber was placed in the neutral axis of the specimen. The neutral axis for the specimens used in the present study was 
halfway between the upper surface of the specimen and the tip of the precrack. Higher fracture toughness values may be expected if the fiber reinforcement is positioned closer to the tip of the precrack, further away from the load.

Samadzadeh et al ${ }^{17}$ reported that polyethylene fiber produced significantly higher fracture load for BAC resin but not for PMMA resin. In the present study, the polyethylene fiber does not produce higher fracture toughness values for either material. The lower fracture toughness for the polyethylene fiber-reinforced specimens in this study may be attributed to poorly bonded fibers, thus creating the equivalent of voids. In addition, the PMMA resin polymer-to-monomer ratio was changed to create a lower viscosity mixture. Although a reduced viscosity should improve impregnation of fibers into the resin, it was shown by Vallittu ${ }^{15}$ that higher monomer content in the mixture would lead to higher polymerization shrinkage of the resin. This higher polymerization shrinkage could cause a split between the fibers and the polymer matrix. Improper impregnation also increases water sorption that might result in a detrimental hydrolytic effect and decreasing mechanical properties of the reinforced resin. ${ }^{15}$ However, the same argument would not be valid for the weaker polyethylene values in the BAC material since the recommended automix ratio was used.

For the PMMA resin, the steel wire group had significantly higher fracture toughness than the polyethylene fiber group, but not significantly higher than the glass fiber group. Similar results were reported by Vallittu et al, ${ }^{12}$ although these authors used a heatpolymerized PMMA resin and measured impact strength. The glass fiber group also had significantly higher fracture toughness than the polyethylene fiber group. This is in agreement with other studies.7,9,15

For the BAC resin, the wire group demonstrated significantly higher fracture toughness than the polyethylene fiber group, but, again, not significantly higher than the glass fiber group. Glass fiber also had significantly higher fracture toughness than the polyethylene fiber group. This finding is supported by Hamza et al.7

It was interesting to compare wire with fiber reinforcement in a single study. Both glass fiber and steel wire reinforcements produced significantly higher fracture toughness for the BAC and PMMA resins. However, the use of wire is limited due to its dimensions and color compared to the glass fiber. Wire provides the clinician with an additional and less expensive option in areas of the mouth where esthetics is not crucial and adequate space is available. For all 3 types of specimens, the reinforcement material held the fragments together. Clinically, this prevents catastrophic failure of the FPD, and decreases patient discomfort and unscheduled appointments. 


\section{Conclusions}

Within the limitations of this study, the following conclusions were drawn:

1. PMMA resin has significantly lower fracture toughness than BAC resin.

2. Glass fiber and stainless steel wire reinforcements produce significantly higher fracture toughness for PMMA and BAC resin compared to polyethylene fiber reinforcement.

3. Reinforcement of both types of resins with stainless steel wire provides the highest fracture strength for the materials tested, but esthetics and availability of space may restrict its use.

4. Where esthetics and space is of concern, the glass fiber seems to be the most appropriate for reinforcing both types of resins. 


\section{References}

1. Wang RL, Moore BK, Goodacre CJ, Swartz ML, Andres CJ. A comparison of resins for fabricating provisional fixed restorations. Int J Prosthodont 1989;2:173-84.

2. Haselton DR, Diaz-Arnold AM, Vargas MA. Flexural strength of provisional crown and fixed partial denture resins. J Prosthet Dent 2002;87:225-8.

3. Koumjian JH, Nimmo A. Evaluation of fracture resistance of resins used for provisional restorations. J Prosthet Dent 1990;64:654-8.

4. Vallittu PK. A review of methods used to reinforce polymethyl methacrylate resin. J Prosthodont 1995;4:183-7.

5. Hamza TA, Rosenstiel SF, El-Hosary MM, Ibraheem RM. Fracture resistance of fiber-reinforced PMMA interim fixed partial dentures. J Prosthodont 2006;15:223-8.

6. Pfeiffer P, Grube L. Effect of pontic height on the fracture strength of reinforced interim fixed partial dentures. Dent Mater 2006;22:1093-7.

7. Chung K, Lin T, Wang F. Flexural strength of a provisional resin material with fibre addition. J Oral Rehabil 1998;25:214-7.

8. Hamza TA, Rosenstiel SF, Elhosary MM, Ibraheem RM. The effect of fiber reinforcement on the fracture toughness and flexural strength of provisional restorative resins. J Prosthet Dent 2004;91:258-64.

9. Kim SH, Watts DC. Effect of glass-fiber reinforcement and water storage on fracture toughness (KIC) of polymer-based provisional crown and FPD materials. Int $\mathrm{J}$ Prosthodont 2004;17:318-22.

10. Vallittu PK. The effect of glass fiber reinforcement on the fracture resistance of a provisional fixed partial denture. J Prosthet Dent 1998;79:125-30.

11. Vallittu PK. Comparison of the in vitro fatigue resistance of an acrylic resin removable partial denture reinforced with continuous glass fibers or metal wires. J Prosthodont 1996;5:115-21.

12. Vallittu PK, Vojtkova H, Lassila VP. Impact strength of denture polymethyl methacrylate reinforced with continuous glass fibers or metal wire. Acta Odontol Scand 1995;53:392-6. 
13. Kanie T, Fujii K, Arikawa H, Inoue K. Flexural properties and impact strength of denture base polymer reinforced with woven glass fibers. Dent Mater 2000;16:150-8.

14. Nohrstrom TJ, Vallittu PK, Yli-Urpo A. The effect of placement and quantity of glass fibers on the fracture resistance of interim fixed partial dentures. Int $J$ Prosthodont 2000;13:72-8.

15. Vallittu PK. Flexural properties of acrylic resin polymers reinforced with unidirectional and woven glass fibers. J Prosthet Dent 1999;81:318-26.

16. Vallittu PK. Compositional and weave pattern analyses of glass fibers in dental polymer fiber composites. J Oral Rehabil 1998;7:170-6.

17. Samadzadeh A, Kugel G, Hurley E, Aboushala A. Fracture strengths of provisional restorations reinforced with plasma-treated woven polyethylene fiber. J Prosthet Dent 1997;78:447-50.

18. Vallittu PK, Narva K. Impact strength of a modified continuous glass fiber-poly(methyl methacrylate). Int J Prosthodont 1997;10:142-8.

19. Solnit GS. The effect of methyl methacrylate reinforcement with silane treated and untreated glass fibers. J Prosthet Dent 1991;66:310-4.

20.Pfeiffer P, Grube L. In vitro resistance of reinforced interim fixed partial dentures. J Prosthet Dent 2003;89:170-4.

21. Vallittu PK. Curing of a silane coupling agent and its effect on the transverse strength of autopolymerizing polymethylmethacrylate-glass fibre composite. J Oral Rehabil 1997;24:124-30.

22. Takagi K, Fujimatsu H, Usami H, Ogasawara S. Adhesion between high strength and high modulus polyethylene fibers by use of polyethylene gel as an adhesive. J Adhesion Sci Technol 1996;10:869-82.

23. Higg WA, Lucksanasombool P, Higgs RJ, Swain MV. Evaluating acrylic and glassionomer cement strength using the biaxial flexure test. Biomaterials 2001;22:1583-90.

24. Anderson TL. Fracture mechanics: Fundamentals and applications. $3^{\text {rd }}$ ed. Boca Raton: CRC Press; 2005. p. 299.

25. Uctasli S, Harrington E, Wilson HJ. The fracture resistance of dental materials. J Oral Rehabil 1995;22:877-86. 


\section{Legends}

Fig. 1. Custom-made stainless steel mold, demonstrating stops (a) with depth of $1.5 \mathrm{~mm}$ for positioning of reinforcement and position of scalpel (b) to create precrack.

Fig. 2. Specimen demonstrating dimensions. Width $(B=3 \mathrm{~mm})$, height $(\mathrm{W}=6 \mathrm{~mm})$, precrack $(A=3 \mathrm{~mm})$, span between supports $(\mathrm{L}=20 \mathrm{~mm})$. Position of reinforcement is indicated by dotted line at distance of $1.5 \mathrm{~mm}$ from upper surface of specimen, as determined by stops in template.

Fig 3. Side-by-side box plot of fracture toughness $\left(\mathrm{K}_{\mathrm{IC}}\right.$ in $\left.\mathrm{MNm}^{-1.5}\right)$ for 4 PMMA groups. Dots represent outliers. PMMA = polymethyl methacrylate resin, glass = glass fiber, $\mathrm{PE}$ $=$ polyethylene fiber, wire $=$ stainless steel wire.

Fig. 4. Side-by-side box plot of fracture toughness $\left(\mathrm{K}_{\mathrm{IC}}\right.$ in $\left.\mathrm{MNm}^{-1.5}\right)$ for $4 \mathrm{BAC}$ groups. Dot represents 1 outlier. $\mathrm{BAC}=$ bis-acryl composite resin, glass $=$ glass fiber, $\mathrm{PE}=$ polyethylene fiber, wire $=$ stainless steel wire . 
Figure 1

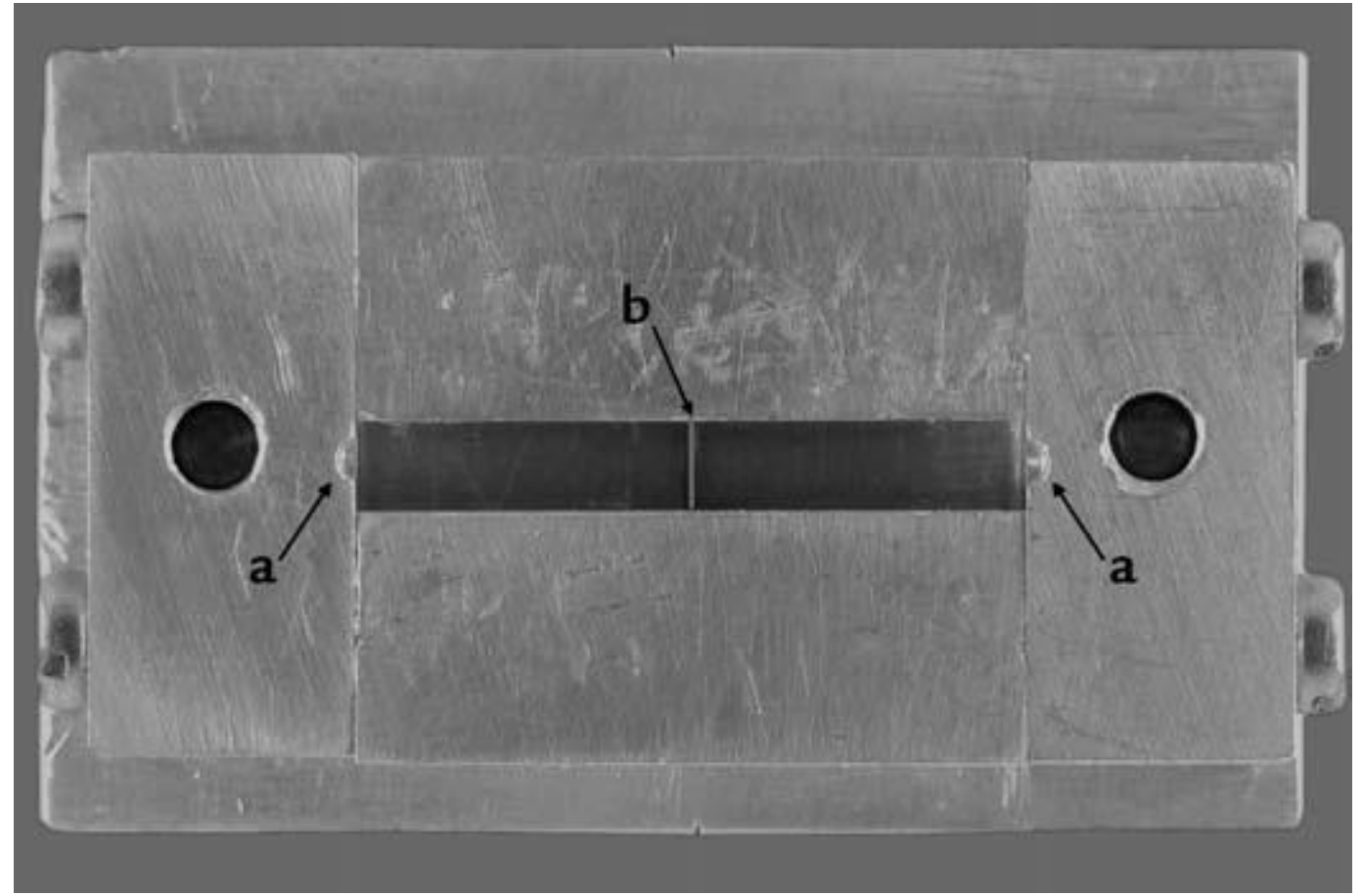

Figure 2

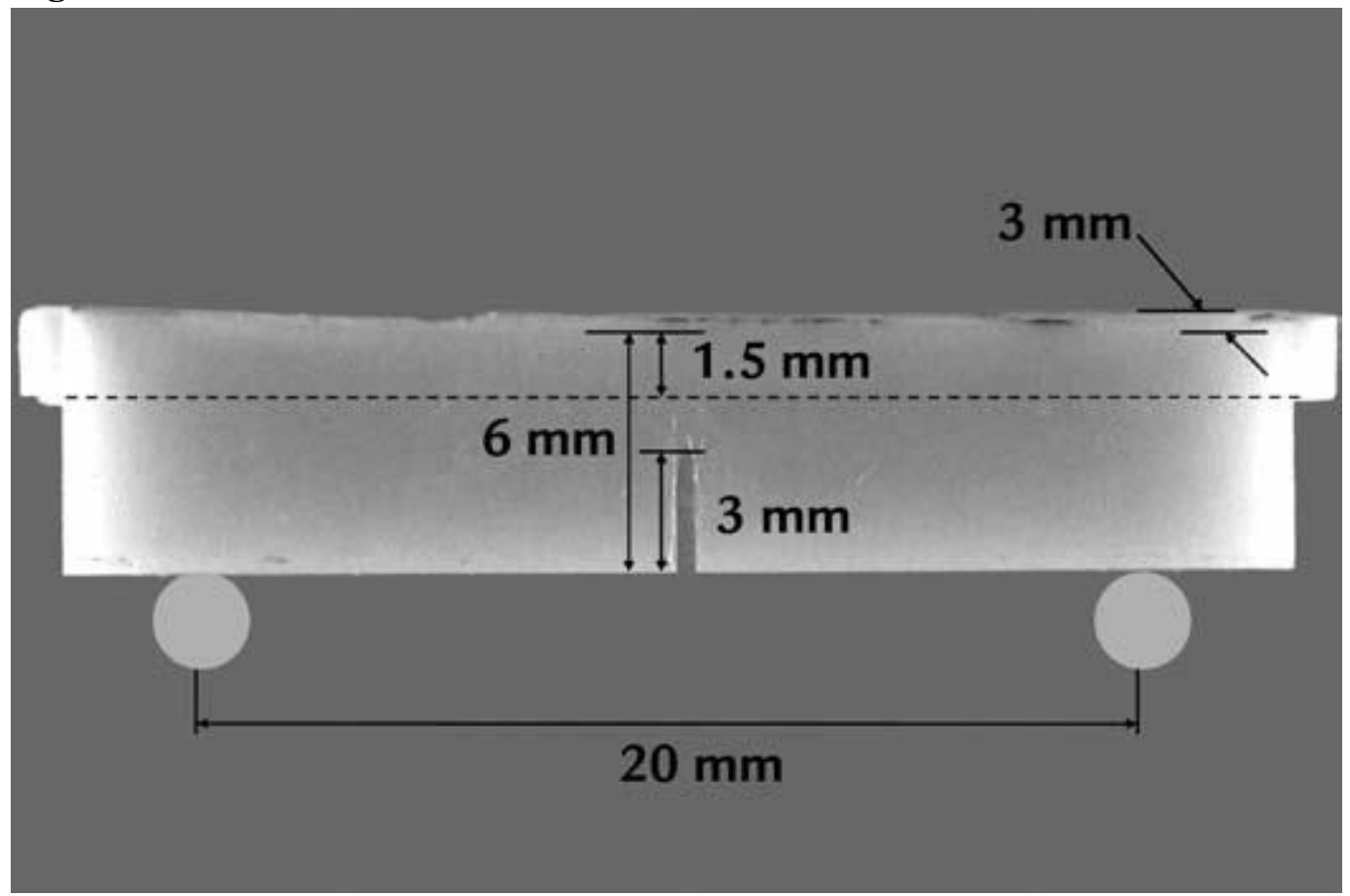


Figure 3

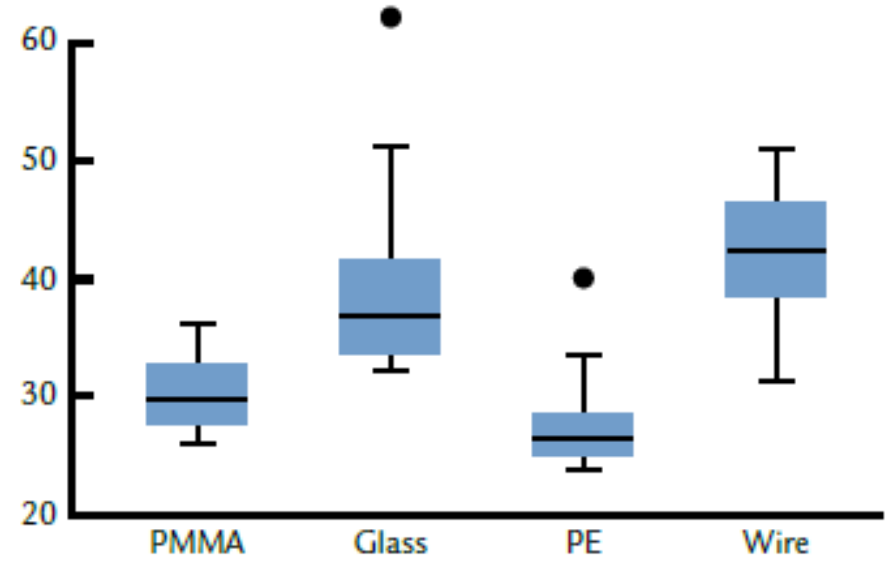

Figure 4

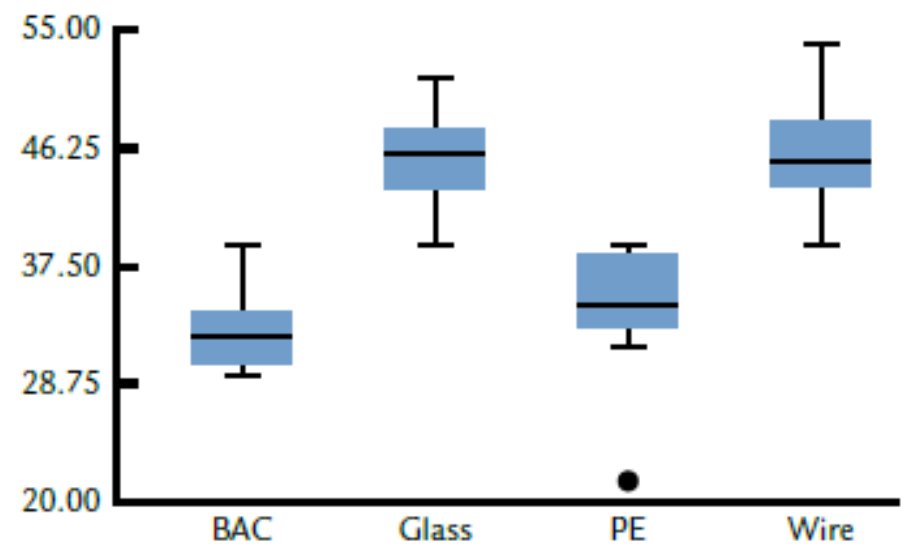

